\title{
Identification of $\beta$-nerve growth factor in dromedary camel seminal plasma and its role in induction of ovulation in females
}

\author{
Fatnassi Meriem ${ }^{1,2}$, Cebrián-Pérez José Alvaro³, Salhi Imed', Pérez-Pé Rosaura ${ }^{3}$, Seddik Mabrouk Mouldi', \\ Casao Adriana ${ }^{3}$, Khorchani Touhami' ${ }^{1}$, Muiño-Blanco Teresa ${ }^{3}$, Hammadi Mohamed ${ }^{1 *}$ \\ ${ }^{1}$ Livestock and Wildlife Laboratory, Arid Lands Institute, 4100 Médenine, University of Gabès, Tunisia, ${ }^{2}$ Higher Institute of Agricultural Science \\ of Chott-Mariem, 4042 Chott-Mariem (Sousse), Tunisia, ${ }^{3}$ Department of Biochemistry and Molecular and Cell Biology, IUCA, School of \\ Veterinary Medicine, University of Zaragoza-IUCA, Zaragoza, Spain
}

\section{A B S T R A C T}

\begin{abstract}
The main objective of this study was to demonstrate the effect of seminal plasma ovulation inducing factor (OIF) on ovulation in female camels. Seminal plasma was fractionated using gel filtration chromatography, and two protein peaks were obtained and analysed by western blotting. The effect of the bioactive protein fraction (OIF/ $\beta-N G F$ ) was tested by intramuscular injection (1 ml) in synchronized females with the following treatments: PBS (negative control group, $\mathrm{n}=3$ ); $20 \mu \mathrm{g}$ Buserelin (GnRH analogue, positive control group; $\mathrm{n}=3$ ); and purified OIF with doses of 1 and $2 \mathrm{mg}(\mathrm{n}=5$, each treatment). Blood samples were collected every two days from day 0 until 14 days post-treatment, and the progesterone concentration was assessed. The obtained results showed that the OIF is highly present in the seminal plasma of dromedary camels as a protein with a molecular mass of approximately $14 \mathrm{kDa}$. It was detected as a betaNerve Growth Factor, named Cam- $\beta$-NGF. The effect of this molecule on ovulation was clearly demonstrated by the significant increase of the plasma progesterone concentration in the treated female groups (1 and $2 \mathrm{mg}$ of Cam- $\beta$-NGF) as observed in Buserelin group. In summary, intramuscular injection of $\beta$-NGF isolated from dromedary camel seminal plasma induces ovulation in females with similar rate to Buserelin treatment.
\end{abstract}

Keywords: $\beta$-nerve growth factor; Dromedary camel; Ovulation; Seminal plasma

\section{INTRODUCTION}

Ovulation in mammals is controlled by a complex neuroendocrine mechanism including signalling pathways connecting the reproductive organs and the brain. Mammalian species have been classified as either induced or spontaneous ovulators, depending on the stimulation system of GnRH release from the hypothalamus (Bakker and Baum, 2000). Camelids are considered inducedovulatory species, given that the preovulatory LH surge can take place after natural coitus (Marie and Anouassi, 1986; Hammadi, 2003) or intramuscular injection of seminal plasma (SP) (Pan et al., 2001; Ratto et al., 2005).

The evidence of an ovulation inducing factor (OIF) has been firstly reported in SP of Bactrian camels (Chen et al., 1985; Pan et al., 2001) and ovulation occurred after intravaginal or intramuscular/intrauterine administration of SP to female Bactrian camels (Zhao et al., 2001; Li and Zhao, 2004). Following studies demonstrated also the presence of this factor in SP of llamas (Adams et al., 2005; Ratto et al., 2012; Silva et al., 2014) and alpacas (Ratto et al., 2005; Kershaw-Young et al., 2012). In llamas, OIF was described as a protein with a molecular weight of approximately $14 \mathrm{kDa}$ that displays a potent ovulatory effect, resistant to heat-shock and enzymatic digestion with proteinase (Ratto et al., 2010; Ratto et al., 2011). In fact, the intramuscular administration of this protein factor provokes ovulation via the release of a preovulatory LH surge, suggesting an endocrine effect at the central level of the hypothalamic-pituitary axis (Adams et al., 2005; Ratto et al., 2011; Ulloa-Leal et al., 2014). More recent, a proteomic study revealed that OIF from llama has a molecular mass of $13.221 \mathrm{kDa}$, and a database search

\footnotetext{
*Corresponding author:

Hammadi Mohamed, Livestock and Wildlife Laboratory, Arid Lands Institute, 4100 Médenine, University of Gabès, Tunisia.

Tel: +21675633005; Fax: +21675633006;. E-mail: mohamed.hammadi@ira.rnrt.tn

Received: 03 November 2016; Revised: 30 January 2017; Accepted: 01 February 2017; Published Online: 15 February 2017
} 
showed that the 12-23 amino-acid sequence of OIF had a high homology with the sequence of the $\beta$-Nerve Growth Factor $(\beta-N G F)$ of human, porcine, bovine and murine species (Ratto et al., 2012). The isolation and identification of $\beta$-NGF from dromedary camel seminal plasma was conducted by Kumar et al. (2013), who showed that this factor has a molecular mass of $22 \mathrm{kDa}$ with a MASCOT score of 118 and 2 matched peptides. However, the ovulation inducing capacity of dromedary camel $\beta$-NGF has not been demonstrated. Taking into account the known effects of OIF/ $\beta$-NGF in camelids species (Pan et al., 1992; Ratto et al., 2011; Kershaw-Young et al., 2012; Berland et al., 2016), we hypothesized that OIF/ $\beta$-NGF from dromedary camel seminal plasma might induce ovulation and provoke an increase in the progesterone concentration. Therefore, the aim of the present study was to purify and evaluate the ovulatory effect of the intramuscular administration of $\beta$-NGF isolated from dromedary camel seminal plasma.

\section{MATERIALS AND METHODS}

\section{Animals and management}

The study was carried outat the Arid Lands Institute's experimental station in Médenine, Tunisia $\left(33^{\circ} 30^{\prime} \mathrm{N}\right.$, $10^{\circ} 40^{\prime} \mathrm{E}$ and $18 \mathrm{~m}$ above sea level). The procedures were performed according to the protocols of the Tunisian Ministry of the Higher Education and Scientific Research in accordence with EC regulations.

\section{Males}

Six clinically healthy male dromedary camels, ranging in age from 6 to 17 years, with a mean body weight of $545 \pm 63 \mathrm{~kg}$ and good body condition score $(3.8 \pm 0.7$ arbitrary units from 0 to 5, according to Faye et al., 2001) were used for semen collection. The camels were managed as previously described (Fatnassi et al., 2014).

\section{Females}

A total of 16 non-lactating and fertile female camels aged between 7 and 20 years and having a $419 \pm 41 \mathrm{~kg}$ body weight were used from March to April 2015. Dams were kept in pen and daily moved to salty pastureduring 6 to $7 \mathrm{~h}$ and providedsupplementary barely straw, concentrate (crude protein 11\%, ash $8 \%$, neutral detergent fiber $32 \%$ ), and water once a day.

\section{Seminal plasma preparation}

Semen was collected twice a week during December to March using a bovine artificial vagina and a female camel maintained in a couched position. After collection, ejaculates were kept in a water bath $\left(36^{\circ} \mathrm{C}\right)$ until liquefaction (60-180 min). Used ejaculates were characterized by volume $=10.6 \pm 7.3 \mathrm{ml}$, mass motility $=2.8 \pm 1.1($ score $0-5)$, viability $=56.4 \pm$ $10.6 \%$ and concentration $=686.6 \pm 375.5 \times 10^{6} \mathrm{spz} / \mathrm{ml}$. To obtain seminal plasma, semen samples were subjected to 2 successive washings by centrifugation at $10.000 \mathrm{~g}$ for $10 \mathrm{~min}$, at room temperature (RT). The protein concentration of seminal plasma was measured by spectrophotometry (Biuret method) and samples containing more than $12 \mathrm{mg} / \mathrm{ml}$ were pooled and stored at $-80{ }^{\circ} \mathrm{C}$ until use in further assays.

\section{Seminal plasma protein purification}

The protein purification procedure was performed according to the process described by Ratto et al. (2011). In brief, $2 \mathrm{ml}$ (35-40 $\mathrm{mg}$ of protein) of camel seminal plasma was fractionated by fast protein liquid chromatography (FPLC, GE Healthcare Life Sciences, Bjorkgatan, Sweden) using a gel filtration column (SEC, Hi PrepTM 26/60 SephacrylTMS-100, GE Healthcare Life Sciences, Bjorkgatan, Sweden). The purification was carried out at RT at a flow rate of $0.5 \mathrm{ml} / \mathrm{min}$ and the elution was performed isocratically using phosphate buffered saline (PBS) at $\mathrm{pH} 7.4$ as a mobile phase. The eluate was collected in $2 \mathrm{ml}$ fractions and the absorbance at $280 \mathrm{~nm}$ was measured with a UV 280 detector. In these conditions, two protein peaks were obtained and corresponding fractions were pooled separately and stored at $-20^{\circ} \mathrm{C}$ until utilization.

\section{SDS PAGE and densitometry quantification}

The pools of the two isolated peaks were concentrated using ultra-filters (Amicon ${ }^{\circledR}$ Ultra-15 Centrifugal Filter Devices, Merck Millipore Corporation, Darmstadt, Germany) with a nominal molecular weight limit of $3.0 \mathrm{kDa}$. Protein concentration was measured using the Bradford method (1976). Whole dromedary camel seminal plasma (CSP) and the two isolated fractions (P1 and P2) were analysed before loading onto polyacrylamide gels.

SDS-PAGE electrophoresis was carried out according to Laemmli (1970). Briefly, protein band profiles in CSP, P1 and $\mathrm{P} 2$ were examined by 14\% polyacrylamide gels under denaturing conditions after loading $5 \mu \mathrm{g}$ of protein of each sample. Electrophoresis was performed at $130 \mathrm{~V}$ and $4{ }^{\circ} \mathrm{C}$ for $90 \mathrm{~min}$. A mixture of pre-stained molecular weights ranging from 10 to $250 \mathrm{kDa}$ (Bio-Rad, Hercules, CA, USA) was used as a standard marker. Proteins were stained with Coomassie blue stain (R-250, Serva, Heidelberg, Germany). Gels were imaged with the Odyssey Infrared Imaging system (Odyssey®, LI-COR Biosciences, Lincoln, USA) in the $700 \mathrm{~nm}$ channel. Densitometry quantification of the protein bands present in the gel was performed using the publicly available ImageJ software (IJ 1.50b) in accordance with published guidelines (Ferreira and Rasband, 2012). 


\section{Western blot}

The beta nerve growth factor ( $\beta$-NGF) was detected by western blot according to the protocol used by Druart et al. (2013) with some modifications. Five $\mu \mathrm{g}$ of protein from CSP, P1 and P2 was loaded on each lane of 14\% polyacrylamide gel. A recombinant Human $\beta$-NGF (Gibco ${ }^{\circledR}$, Life technologies ${ }^{\mathrm{TM}}$, New York,USA) was also loaded onto the gel as a positive control. Separated proteins were transferred onto an Immobilon-PVDF transfer membrane (midi format, $0.2 \mu \mathrm{m}$ PVDF, Transfer Pack, Bio-Rad, Hercules, CA, USA) and blotted using the Trans Blot ${ }^{\circledR}$ Turbo ${ }^{\mathrm{TM}}$ blotting system (Bio-Rad, Hercules, CA, USA) at a constant $2.5 \mathrm{~A}$ up to $25 \mathrm{~V}$ for $10 \mathrm{~min}$. After transference, the membranes were blocked with $5 \%$ BSA dissolved in PBS for $2 \mathrm{~h}$ at RT under shaking. Then, $\beta$-NGF was detected by incubating the membrane with rabbit polyclonal antibody raised against human NGF (NGF (H-20): sc-548, Santa Cruz Biotechnology, INC, Heidelberg, Germany), diluted 1/1,000,000 (v/v) in phosphate buffered saline with $0.1 \%(\mathrm{v} / \mathrm{v})$ Tween 20 (PBST) and $1 \%(\mathrm{w} / \mathrm{v}) \mathrm{BSA}$, under mild agitation overnight at $4{ }^{\circ} \mathrm{C}$. Following incubation with the primary antibody, the blotting membrane was washed three times for $15 \mathrm{~min}$ with PBST. A secondary antibody IRDye ${ }^{\circledR} 800 \mathrm{CW}$ donkey anti rabbit (LI-COR ${ }^{\circledR}$ Biosciences, Lincoln, USA) was diluted in PBST with $1 \%$ BSA $(1 / 100,000 \mathrm{v} / \mathrm{v})$ and the membrane was incubated for $1 \mathrm{~h}$ and $15 \mathrm{~min}$ at RT. After incubation with the secondary antibody, the membrane was washed again and revealed using Odyssey (Odyssey ${ }^{\circledR}$, LI-COR Biosciences, Lincoln, USA) in the 700 and $800 \mathrm{~nm}$ channels.

\section{Synchronization of females and treatments}

Female camels were subjected to estrus synchronization protocol according to Skidmore et al. (2009) with modification. Briefly, each female was injected intramuscularly (i.m.) on day 0 with $500 \mu \mathrm{g}$ cloprostenol, a prostaglandin analogue (Estrumate, Essex Animal Health Friesoythe, Germany) to remove any existing corpus luteum from the ovaries, followed by $20 \mu \mathrm{g}$ of Buserelin, a GnRH analogue (i.m, Receptal, Intervet, Beaucouze Cedex, France) 7 days later to induce ovulation and synchronize the emergence of the next follicular wave. Fourteen days after the GnRH analogue injection, the synchronized camels were divided into four groups, and each group was then randomly assigned to treatments.

In the light of previous studies that reported an ovulatory response above $90 \%$ using $1 \mathrm{mg}$ of either llama or alpaca $\beta$-NGF (Ulloa-Leal et al., 2014; Stuart et al., 2014), a dose of $1 \mathrm{mg}$ of P2/Cam- $\beta$-NGF was used. Furthermore, we also tested a dose of $2 \mathrm{mg}$ of P2/Cam- $\beta$-NGF based on the body weight of female dromedary camel compared to llama and alpaca females.
The IM doses were as follows:

- Group1: $1 \mathrm{ml}$ PBS (negative control group; $\mathrm{n}=3$ )

- Group 2: $20 \mu \mathrm{g}$ Buserelin (GnRH analogue, positive control group; $\mathrm{n}=3$ )

- Group 3: $1 \mathrm{mg}$ Dromedary camel $\beta$-NGF (Cam- $\beta$ NGF; $\mathrm{n}=5$ )

- Group 4: 2 mg Cam- $\beta$-NGF $(n=5)$.

\section{Blood sampling and progesterone assays}

Ovulation was defined as an increase in blood progesterone concentration above $1 \mathrm{ng} / \mathrm{ml}$ during the $2^{\text {nd }}$ period of luteal phase. For this, blood samples were taken on day 0 (just before treatments) and every 2 days until day 14 post treatment in order to measure plasmatic progesterone concentration. Blood was collected from the jugular vein into EDTA-tubes, centrifuged at $4{ }^{\circ} \mathrm{C}$ for $15 \mathrm{~min}$ at $1500 \mathrm{~g}$, and the plasma was stored at $-20{ }^{\circ} \mathrm{C}$ until analysis. The plasma progesterone concentration was assessed using a radio-immunoassay kit (Immunotech Ref 1188, Beckman Coulter, Marseille, France). Samples were analysed in duplicate with variation coefficients of intra-and interassays of 8.2 and $8.7 \%$, respectively. The sensitivity of the assay was $0.1 \mathrm{ng} / \mathrm{ml}$.

\section{Statistical analyses}

Data of plasma progesterone concentration were analysed by the NPAR1WAY procedure of SAS (SAS 9.3, 2012) using Kruskal-Wallis test. The progesterone profile was divided into 3 phases in accordance with Marie and Anouassi (1987) (0-4 days, 6-10 days, 12-14 days) to test with accuracy the variation between the four treatments. The results were expressed as mean \pm standard error and the $P$-level was set at 0.05 .

\section{RESULTS}

Two protein peaks (P1 and P2) were detected after filtration of the dromedary camel seminal plasma. The purification procedure was repeated twenty times, and very similar chromatograms were obtained under the same elution conditions (Fig. 1).

Protein profiles of both whole dromedary camel seminal plasma (CSP) and the two isolated peaks (P1 and P2) obtained by SDS-PAGE (14\%) under denaturing conditions are shown in Fig. 2A. A main protein band of an approximate molecular weight of $14 \mathrm{kDa}$ was identified in both CSP and P2. However, this protein band was present in a very low proportion in the first isolated peak (P1).Quantitatively, an ImageJ gel densitometry analysis estimated that the proportion of the $14 \mathrm{kDa}$ protein band in CSP was approximately $45 \%$ of the total protein content and approximately $88 \%$ in $\mathrm{P} 2$. 
Western blot analysis allowed us to detect $\beta$-Nerve Growth Factor ( $\beta-\mathrm{NGF}$ ) in both CSP and the second peak (P2) isolated by FPLC (Fig. 2B). Recombinant Human $\beta$-NGF used as a positive control revealed a band about $14 \mathrm{kDa}$ compatible with the predicted molecular weight for $\beta$-NGF.

The plasma progesterone profiles obtained in the four treatment groups are presented in Fig. 3. A significant effects of the type of treatment $\left(d d l=3 ; \chi^{2}=24.63 ; P<0.0001\right)$, and the days following treatment $\left(d d l=7 ; \chi^{2}=56.60 ; P<0.0001\right)$ were found. The progesterone concentration increased significantly after IM injection of Buserelin $(P=0.0046)$, $1 \mathrm{mg}(P=0.0002)$ and $2 \mathrm{mg}(P=0.0017)$ of Cam- $\beta$-NGF, whereas no significant difference was observed after PBS treatment $(P=0.5083)$. The rise in the plasma progesterone concentration took place from day 6 after treatment of females with either $1 \mathrm{mg}$ of Cam- $\beta$-NGF (5/5) or $2 \mathrm{mg}$ of Cam- $\beta$-NGF (4/5), similar to the positive control group treated with Buserelin (3/3). However, this increase was not found in females treated with PBS $(0 / 3)$, which showed a basal progesterone level $(<1 \mathrm{ng} / \mathrm{ml})$. In all treatment groups, the plasma progesterone concentration remained basal during the 4 first days post-treatment (Table 1). During the second phase (6-10 days), the progesterone concentration did not significantly differ between the Buserelin, $1 \mathrm{mg}$ and $2 \mathrm{mg}$ Cam- $\beta$-NGF groups, while the concentration in the PBS group was significantly lower than that of the other three groups. During the third phase (12 - 14 days), the progesterone concentration returned to the basal level.

\section{DISCUSSION}

The present study is the first attempt to demonstrate the role of the $\beta$-NGF purified from the seminal plasma of the dromedary camel as an in vivo ovulation-inducing factor operating by increasing the progesterone concentration. Two protein peaks were isolated from the seminal plasma using gel exclusion chromatography, similar to that previously reported for llama seminal plasma using a combination of hydroxyapatite and gel-filtration chromatography (Ratto et al., 2011). However, six protein fractions were obtained after separation of Bactrian camel seminal plasma ( $\mathrm{Li}$ and

Table 1: Ovulation rates and variation of progesterone concentration $(\mathrm{ng} / \mathrm{ml})$ among phases

\begin{tabular}{lcccc}
\hline Treatments & $\begin{array}{c}\text { Ovulation } \\
\text { rate }\end{array}$ & $\begin{array}{c}\text { Phase 1 } \\
(\mathbf{0 - 4} \text { day) }\end{array}$ & $\begin{array}{c}\text { Phase 2 } \\
(6-10 \text { day })\end{array}$ & $\begin{array}{c}\text { Phase } 3 \\
(12-14 \text { day })\end{array}$ \\
\hline PBS & $0 \%(0 / 3)$ & $0.1 \pm 0.1$ & $0.1 \pm 0.1^{\mathrm{b}}$ & $0.1 \pm 0.1$ \\
Buserelin & $100 \%(3 / 3)$ & $0.2 \pm 0.1$ & $3.2 \pm 0.6^{\mathrm{a}}$ & $0.2 \pm 0.1$ \\
$1 \mathrm{mg}$ P2/Cam- $\beta-\mathrm{NGF}$ & $100 \%(5 / 5)$ & $0.2 \pm 0.1$ & $3.0 \pm 0.5^{\mathrm{a}}$ & $0.2 \pm 0.4$ \\
$2 \mathrm{mg} \mathrm{P} 2 /$ Cam- $\beta-\mathrm{NGF}$ & $80 \%(4 / 5)$ & $0.4 \pm 0.1$ & $3.3 \pm 0.5^{\mathrm{a} *}$ & $0.2 \pm 0.4$ \\
\hline
\end{tabular}

Data are the mean \pm SE. Within columns, values with different superscript letters differ significantly $(\mathrm{P}<0.05)$. *: average value of ovulated animals in the group. (Phase 1: $0-4$ days; Phase 2: $6-10$ days, Phase

3: $12-14$ days) and treatment groups: PBS $(n=3)$, Buserelin $(n=3), 1 \mathrm{mg}$ of P2/Cam- $\beta$-NGF $(n=5), 2$ mg of P2/Cam- $\beta$-NGF $(n=5)$
Zhao, 2004) and three protein peaks were eluted after purification of dromedary camel seminal plasma using a sequential separation procedure (Kumar et al., 2013). The variability of protein fractions could be explained by the differences in the purification procedures and the protein concentration in seminal plasma of camelid species. In literature, protein concentration in seminal plasma averages $22 \mathrm{mg} / \mathrm{ml}$ in Bactrian camel (Mosaferi et al., 2005), and ranges from 2.0 to $25.9 \mathrm{mg} / \mathrm{ml}$ in dromedary camel (El-Manna et al., 1986; Hammadi et al., 2012; Vyas et al., 2014) and from 2.9 to $43.6 \mathrm{mg} / \mathrm{ml}$ in alpaca (Stuart et al., 2014).

Similar to the result of Ratto et al. (2011), an abundant protein having a molecular mass near to $14 \mathrm{kDa}$ was found in both CSP and P2 fraction, and identified as a $\beta-N G F$

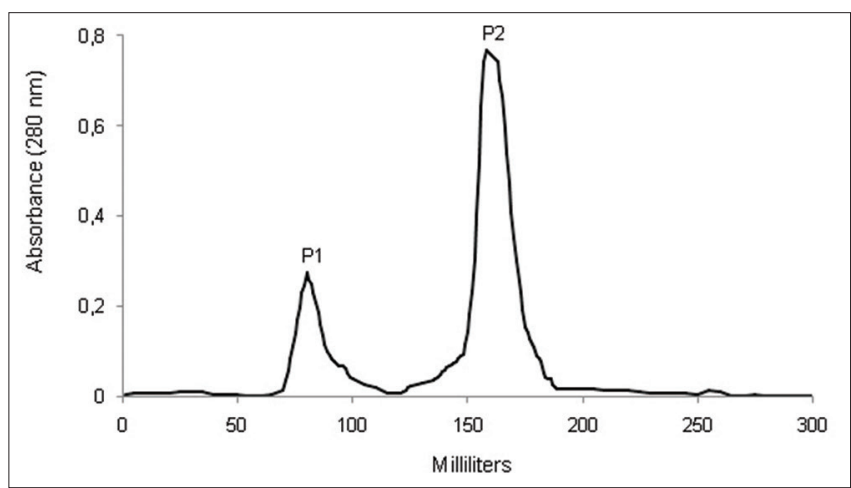

Fig 1. Protein chromatography profile of dromedary camel seminal plasma obtained after purification by fast protein size-exclusion liquid chromatography (FPLC).

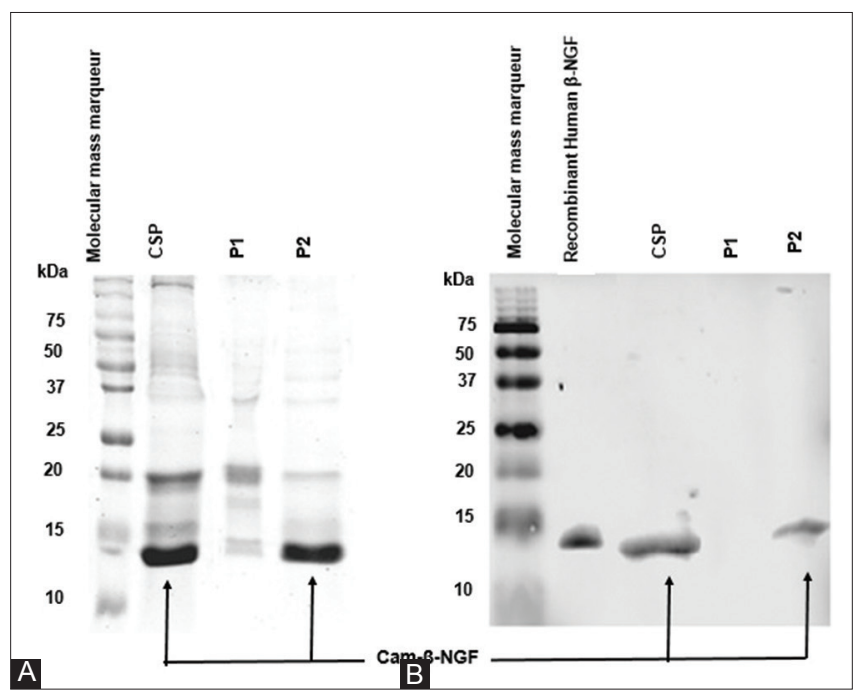

Fig 2. (A) Representative SDS-PAGE profiles of whole dromedary camel seminal plasma (CSP) proteins and the two peaks (P1 and P2) isolated by molecular exclusion chromatography. Identical protein amounts $(5 \mu \mathrm{g})$ of CSP, P1 and P2 were loaded onto 14\% polyacrylamide gels and separated under denaturing conditions. (B) Detection of $\beta$-Nerve Growth Factor ( $\beta$-NGF) in camel seminal plasma (CSP) and the two isolated peaks (P1 and P2) by western blotting using a recombinant Human $\beta$-NGF as a positive control, and a rabbit anti- $\beta$-NGF primary antibody. 


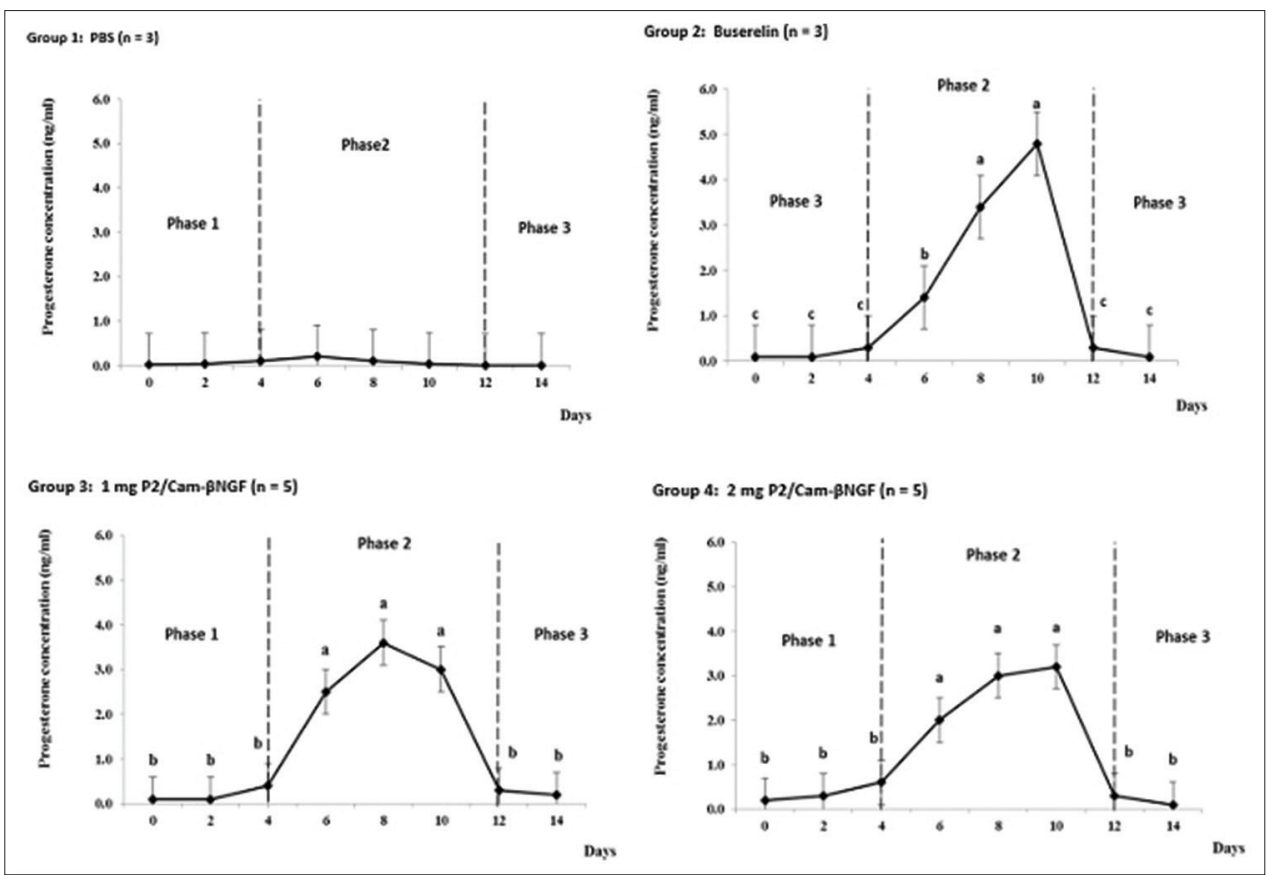

Fig 3. Mean progesterone concentration in blood plasma $(\mathrm{ng} / \mathrm{ml})$ of female camels after intramuscular injection of $(A) 1 \mathrm{ml}$ of phosphate buffered saline (PBS, negative control; $n=3$ ), (B) $20 \mu \mathrm{g}$ Buserelin (GnRH analogue, positive control; $n=3$ ), (C) $1 \mathrm{mg}$ of $\mathrm{P} 2 / \mathrm{Cam}-\beta-\mathrm{NGF}(\mathrm{n}=5)$ or (D) 2 $\mathrm{mg}$ of $\mathrm{P} 2 / \mathrm{Cam}-\beta-N G F(n=5)$. Different superscript letters indicate significant difference $(P<0.05)$.

by Western Blot. The proportion of this protein in CSP was considerably higher than that found by Druart et al. (2013) in dromedary camel seminal plasma (24\%) and comparable to that in alpaca (47\%).Previous studies on small camelids showed that $\beta-\mathrm{NGF}$ is a $26 \sim 27 \mathrm{kDa}$ homodimer that is reduced to 2 dimers of approximately $14 \mathrm{kDa}$ under denaturing conditions (Kershaw-Young et al., 2012; Ratto et al., 2012).Although, a proteomic study conducted by Kumar et al. (2013) revealed a $22 \mathrm{kDa}$ molecular mass of $\beta$-NGF purified from dromedary camel seminal plasma.

The relevant effect of Cam- $\beta$-NGF on inducing ovulation was confirmed by a significant rise in progesterone concentration. Indeed, the intramuscular injection of P2 fraction (Cam- $\beta$-NGF) produced a similar significant increase in plasma progesterone as Buserelin treatment. This is consistent with previous results relating to the injection of seminal plasma in either llamas(Adams et al., 2005; Ratto et al., 2011; Ulloa-Leal et al., 2014) or alpacas (Adams et al., 2005; Kershaw-Young et al., 2012), which induced ovulation evoking a significant increase of progesterone secretion. The increased progesterone concentration could be explained by the indirect Cam- $\beta$ NGF action on the establishment of corpus luteum.

The progesterone profile obtained after injection with Buserelin and 1 or $2 \mathrm{mg}$ Cam- $\beta$-NGF was similar to the normal profile of corpus luteum development following natural mating (Marie and Anouassi, 1987; Skidmore et al.,
1996; Hammadi, 2003) or ovulation induction treatment (Skidmore et al., 1996; Nagy et al., 2005). However, it was different to that of luteinized follicles; progesterone concentration rose for a short period of time and the regression started later and lasted longer (Skidmore et al., 1996).

NGF is a neuropeptide involved in many functions such as ovulation in some mammals (Dissen et al., 1996). Naturally, the seminal plasma factor deposited in the uterine cavity reaches rapidly the systemic circulation to elicit the release of LH. In the recent work of Berland et al. (2016), it was demonstrated that circulation $\beta$-NGF level in llama increases within 15 min after mating with intact male or seminal plasma treatment and incites the release of LH surge and ovulation. In absence of seminal plasma (mating with urethro-male), systemic $\beta$-NGF concentration remains low and no ovulation occurs. All of this confirms that ovulation in camelid species is provoked by semenderived chemical signals via neuroendocrine pathways (Berland et al., 2016). However, the exact route of action of the $\beta$-NGF on LH secretion is not clear; suggesting an action in the hypothalamus level would stimulate the GnRH secretion (Silva et al., 2011) or a direct effect on the anterior pituitary causing the release of LH (Paolicchi et al., 1999; Bogle et al., 2012).

Concerning the dose response, it is clear that the IM injection of $1 \mathrm{mg}$ P2/Cam- $-\mathrm{NGF}$ induces ovulation in all treated dromedary camel. Referring to the $88 \%$ rate of 
purity of the $\beta$-NGF in P2, we can assume that the used quantity of this peptide is equal to $880 \mu \mathrm{g}$. Comparable results were found using $1 \mathrm{mg}$ of a commercial NGF protein in alpacas (Stuart et al., 2014) and $1 \mathrm{mg}$ of purified llamas seminal plasma (Ulloa-Leal et al., 2014). The dose $2 \mathrm{mg}$ P2/Cam- $\beta$-NGF used in the present study leads to similar results compared to $1 \mathrm{mg}$ dose. Then, it is may be better in further works to test less than $1 \mathrm{mg}$ of purified Cam- $\beta$-NGF, giving that a low dose $(125 \mu \mathrm{g})$ of OIF/NGF induced ovulation in llamas (Tanco et al., 2011).

According to the ovulation rate $(80-100 \%)$ obtained in this study, it is clear that almost all females had growing follicles having a diameter between 0.9 and $1.9 \mathrm{~cm}$ (Skidmore et al., 1996) in day 14 post treatment with GnRH. Under this range of preovulatory follicle size, female camels respond in the same way to the ovulation induction treatments with either $20 \mu \mathrm{g}$ of Buserelin or 1 or $2 \mathrm{mg}$ of $\mathrm{P} 2 / \beta$-NGF purified from dromedary camel seminal plasma, showing a very similar progesterone profiles. However, Silva et al. (2014) showed that llamas treated with $1 \mathrm{mg}$ of purified OIF/NGF produced greater plasma progesterone at day 8 compared to those treated with $\mathrm{GnRH}$, irrespective to the pre-ovulatory follicle diameter at the time of treatment.

In conclusion, the OIF is highly abundant in dromedary camel seminal plasma and was identified as a $\beta$-Nerve Growth Factor "Cam- $\beta$-NGF". The results support our hypothesis that intramuscular administration of Cam- $\beta$ NGF induces ovulation at similar rates like GnRH. This study opens up interesting new perspectives for knowing the exact mechanism of action of this molecule on induction ovulation, and for assessing the ability of OIF as a protocol for synchronizing the ovulation in this species. Additionally, the quantification of $\beta$-NGF in seminal plasma and the relationship between its concentration and sperm quality deserve investigation.

\section{ACKNOWLEDGMENTS}

This work was realized in collaboration between the Arid Lands Institute (Medenine, Tunisia) and the School of Veterinary Medicine (Zaragoza, Spain). It was jointly supported by grants CICYT-FEDER AGL 2013- 43328Pand DGA A-26 and the Tunisian Ministry of Higher Education and Scientific Research. The authors thank Dr. Mauricio. J. Silva for helpful suggestions to improve the text. They are grateful to the Tunisian authorities and thank all the technicians at the Livestock and Wildlife Laboratory, IRA Médenine, Tunisia for technical assistance with semen collection, animal handling and maintenance, and data collection. We would also like to thank all staff of the department of Biochemistry, Molecular and Cell
Biology in the Faculty of Veterinary Medicine, University of Zaragoza for their valuable help during this study.

\section{Authors' contributions}

The study is part of the PhD dissertation of MF. MF and MH have designed the study. MF realized the fieldwork and drafted manuscript. MF, IS, RPP and AC were involved in the laboratory analyses. TK and TMB provided financial supports.MH made the statistical analyses of data. TMB and $\mathrm{MH}$ revised the manuscript.

\section{REFERENCES}

Adams, G. P., M. H. Ratto., W. Huanca and J. Singh. 2005. Ovulation inducing factor in the seminal plasma of alpacas and llamas. Biol. Reprod. 73: 452-457.

Bakker, J. and M. J. Baum. 2000. Neuroendocrine regulation of $\mathrm{GnRH}$ release in induced ovulators. Front. Neuroendocrinol. 21: 220-262.

Berland, M. A., C. Ulloa-Leal, M. Barría, H. Wright, G. A. Dissen, M. E. Silva, S. R. Ojeda and M. H. Ratto. 2016. Seminal plasma induces ovulation in llamas in the absence of a copulatory stimulus: Role of nerve growth factor as an ovulation-inducing factor. Endocrinology. 157: 3224-3232.

Bogle, O. A., M. H. Ratto and G. P. Adams. 2012. Ovulation-inducing factor (OIF) induces LH secretion from pituitary cells. Anim. Reprod. Sci. 133: 117-122.

Bradford, M. M. 1976. A rapid and sensitive method for the quantitation of microgram quantities of protein utilizing the principle of protein-dye binding. Anal. Biochem. 72: 248-254.

Chen, B. X., Z. X. Yuen and G. W. Pan. 1985. Semen-induced ovulation in the Bactrian camel (Camelus bactrianus). J. Reprod. Fertil. 74: 335-339.

Dissen, G. A., D. F. Hill, M. E. Costa, C. W. Les Dees, H. E. Lara and S. R. Ojeda. 1996. A role for trkA nerve growth factor receptors in mammalian ovulation. Endocrinology. 137: 198-209.

Druart, X., J. P. Rickard, S. Mactier, P. L. Kohnke, C. M. Kershaw-Young, R. Bathgate, Z. Gibb, B. Crossett, G. Tsikis, V. Labas, G. Harichaux, C. G. Grupen and S. P. de Graaf. 2013. Proteomic characterization and cross species comparison of mammalian seminal plasma. J. Proteomics. 91: 13-22.

El-Manna, M. M., M. D. Tingari and A. K. Ahmed. 1986. Studies on camel semen II. biochemical characteristics. Anim. Reprod. Sci. 12: 223-231.

Fatnassi, M., B. Padalino, D. Monaco, T. Khorchani, G. M. Lacalandra and M. Hammadi. 2014. Evaluation of sexual behavior of housed male camels (Camelus dromedarius) through female parades: Correlation with climatic parameters. Trop. Anim. Health Prod. 46: 313-321.

Faye, B., M. Bengoumi, A. Cleradin, A. Tabarani and Y. Chilliard. 2001. Body condition score in dromedary camel: A tool for management of reproduction. Emirates J. Food Agric. 13: 1-6.

Ferreira, T. and W. Rasband. 2012. Image J User Guide. Image Processing and Analysis. Image J Community, 179.

Hammadi, M. 2003. Caractérisation, modulation nutritionnelle et implication du système IGF dans la fonction sexuelle chez la chamelle (Camelus dromedarius). Doctorat en Sciences Agronomiques et Ingénierie Biologique, Faculté Universiraire des Sciences Agronomiques de Gembloux, Belgique.

Hammadi, M., I. Salhi, A. Barmat and T. Khorchani. 2012. Major 
proteins and enzyme gelatinoletic activities in camel seminal plasma. In: Proceedings of the $3^{\text {rd }}$ Conference of the International Society of Camelid Research and Development, Muscat, Oman, pp. 44-45.

Kershaw-Young, C. M., X. Druart, J. Vaughan and W. M. C. Maxwell. 2012. $\beta$-Nerve growth factor is a major component of alpaca seminal plasma and induces ovulation in female alpacas. Reprod. Fertil. Dev. 24: 1093-1097.

Kumar, S., V. K. Sharma, S. Singh, G. R. Hariprasad, G. Mal, A. Srinivasan and S. Yadav. 2013. Proteomic identification of camel seminal plasma: Purification of $\beta$-nerve growth factor. Anim. Reprod. Sci. 136: 289-295.

Laemmli, U. K. 1970. Cleavage of structural proteins during the assembly of the head of bacteriophage T4. Nature. 227: 680-685.

$\mathrm{Li}, \mathrm{X}$. and X. Zhao. 2004. Separation and purification of ovulationinducing factors in the seminal plasma of the Bactrian camel (Camelus bactrianus). Vet. Res. Commun. 28: 235-245.

Marie, M. and A. Anouassi. 1986. Mating-induced luteinizing hormone surge and ovulation in the female camel (Camelus dromedarius). Biol. Reprod. 35: 792-798.

Marie, M. and A. Anouassi. 1987. Induction of luteal activity and progesterone secretion in the nonpregnant one-humped camel (Camelus dromedarius). J. Reprod. Fertil. 80: 183-192.

Mosaferi, S., A. Niasari-Naslaji, A. Abarghani, A. A. Gharahdaghi and A. Gerami. 2005. Biophysical and biochemical characteristics of Bactrian camel semen collected by artificial vagina. Theriogenology. 63: 92-101.

Nagy, P., J. Juhasz and U. Wernery. 2005. Incidence of spontaneous ovulation and development of the corpus luteum in non-mated dromedary camels (Camelus dromedarius). Theriogenology. 64: 292-304.

Pan, G. W., X. X. Zhao, B. H. Chen, S. Jiang, Y. M. Huang, Y. S. Zu and $H$. Y. Wang. 1992. The ovulation-inducing effect of seminal plasma in the Bactrian camel. In: Allen, W. R., A. J. Higgins, I. G. Mayhew, D. H. Snow and J. F. Wade (Eds.), Proceedings of the First International Camel Conference, R\&W Publications, Newmarket, UK, pp. 159-161.

Pan, G., Z. Chen, X. Liu, D. Li, Q. Xie, F. Ling and L. Fang. 2001. Isolation and purification of the ovulation-inducing factor from seminal plasma in the Bactrian camel (Camelus bactrianus). Theriogenology. 55: 1863-1879.

Paolicchi, F., B. Urquieta, L. Del Valle and E. Bustos-Obregon. 1999. Biological activity of the seminal plasma of alpacas: Stimulus for the production of LH by pituitary cells. Anim. Reprod. Sci. 54: 203-210.

Ratto, M. H., W. Huanca, J. Singh and G. P. Adams. 2005. Local versus systemic effect of ovulation-inducing factor in the seminal plasma of alpacas. Reprod. Biol. Endocrinol. 3: 1-29.
Ratto, M. H., W. Huanca and G. P. Adams. 2010. Ovulation-inducing factor: A protein component of llama seminal plasma. Reprod. Biol. Endocrinol. 8: 44.

Ratto, M. H., L. T. J. Delbaere, Y. A. Leduc, R. A. Pierson and G. P. Adams. 2011. Biochemical isolation and purification of ovulation-inducing factor (OIF) in seminal plasma of llamas. Reprod. Biol. Endocrinol. 9: 24.

Ratto, M. H., Y. A. Leduc, X. P. Valderrama, K. E. VanStraaten, L. T. J. Delbaere, R. A. Pierson and G. P. Adams. 2012. The nerve of ovulation inducing factor in semen. Proc. Natl. Acad. Sci. USA. 109: 15042-15047.

SAS Institute. 2012. The SAS System for Windows, Release 9.3, SAS Institute Inc., Cary, NC.

Silva, M. E., J. P. Smulders, M. Guerra, X. P. Valderrama, C. Letelier, G. P. Adams and M. H. Ratto. 2011. Cetrorelix suppresses the preovulatory LH surge and ovulation induced by ovulationinducing factor (OIF) present in llama seminal plasma. Reprod. Biol. Endocrinol. 9: 74.

Silva, M., C. Ulloa-Leal, C. Norambuena, A. Fernández, G. P. Adams and M. H. Ratto. 2014. Ovulation-inducing factor (OIF/NGF) from seminal plasma origin enhances corpus luteum function in llamas regardless the preovulatory follicle diameter. Anim. Reprod. Sci. 148: 221-227.

Skidmore, J. A., M. Billah and W. R. Allen. 1996. The Ovarian follicular wave pattern and induction of ovulation in the mated and nonmated one-humped camel (Camelus dromedarius). J. Reprod. Fertil. 106: 185-192.

Skidmore, J. A., G. P Adams and M. Billah. 2009. Synchronisation of ovarian follicular waves in the dromedary camel (Camelus dromedarius). Anim. Reprod. Sci. 114: 249-255.

Stuart, C. C., J. L. Vaughan, C. M. Kershaw-Young, J. Wilkinson, R. Bathgate and S. P. de Graaf. 2014. Effects of varying doses of $\beta$-nerve growth factor on the timing of ovulation, plasma progesterone concentration and corpus luteum size in female alpacas (Vicugna pacos). Reprod. Fertil. Dev. 27: 1181-1186.

Tanco, V. M., M. H. Ratto, M. Lazzarotto and G. P. Adams. 2011. Dose-response of female llamas to ovulation-inducing factor from seminal plasma. Biol. Reprod. 85: 452-456.

Ulloa-Leal, C. E., O. A. Bogle, G. P. Adams and M. H. Ratto. 2014. Luteotrophic effect of ovulation-inducing factor/nerve growth factor (OIF/NGF) present in the seminal plasma of llamas. Theriogenology. 81: 1101-1107.

Vyas, S., G. Mal and N. V. Patil. 2014. Comparative study of seminal plasma proteins in dromedary camels. Indian J. Anim. Sci. 84: 13-14.

Zhao, X. X., X. L. Li and B. X. Chen. 2001. Isolation of ovulationinducing factors in the seminal plasma of Bactrian camel (Camelus bactrianus) by DEAE-cellulose chromatography. Reprod. Domest. Anim. 36: 177-181. 